\title{
Piloting for interviews in qualitative research: operationalization and lessons learnt
}

\begin{abstract}
Qualitative interviews offer rich and detailed information in understanding peopleôs experiences. However, qualitative inquiry might be difficult for inexperience researcher to adequately perform the interview. Piloting for interview is an integral aspect and useful in the process of conducting qualitative research as it highlights the improvisation to the major study. This article discusses the importance of pilot study, the methods undertaken and the lessons learnt throughout the process. The pilot interview was conducted with two offshore catering employees, as preparation for a dissertation in developing a job satisfaction instrument for offshore catering employees in Malaysia. The useful functions of pilot study are described and in highlighting the advantageous of pilot study, this paper describes the modification made for the major study as a result of the pilot work. These comprise (1) criteria for selecting potential participants, and (2) improving the interview guide, particularly the interview questions.
\end{abstract}

Keyword: Qualitative; Pilot study; Interview; Job satisfaction; Offshore catering 